\title{
Teologia Feminista e a crítica da razão religiosa patriarcal: entrevista com Ivone Gebara
}

\author{
Maria José Rosa do-Nunes ${ }^{1}$ \\ Pontifícia Universidade Católica de São Paulo
}

\begin{abstract}
As religiões, assim como os estudos que tentam compreendê-las e explicá-las, sofreram, nas últimas déca das, de maneira signific a tiva, os impac tos do feminismo, seja como movimento, seja como pensa mento. As reivindic a ções das fiéis variam desde o acesso ao sacerdócio e ao pastorado, no campo cristão, a té o uso do véu, ou sua recusa, entre as muçulmanas. O desenvolvimento de um discurso teológico elaborado por mulheres e distinto, em muitos aspectos, daqueles que escrevem os homens é marcado pela forte influência das idéias feministas. Revisões das interpretações existentes dos textos sagrados e a proposição de novas interp reta ções são uma consta nte entre a s teólog a sfeministas. As doutrinas e a organização institucional têm sido alvo de sua crítica. Ta mbém os cultos rea liza dos porg rup os de mulheres têm se constituíd o como espa ços de contesta ção e de criação imaginativa de novas formas de relacionar-se com suas crenças. Pode-se dizer que nenhuma área das religiões instituíd a s deixou de passa rpelo crivo crític o do olhar feminista. Da mesma forma que Londa Schienbinger ${ }^{2}$ se interroga pelas mudanças operadas na ciência por ação de cientistas feministas, no campo das religiões podemos perguntar-nos pelas significativas mudanças resultantes da prática e do pensamento das mulheres.
\end{abstract}

\footnotetext{
Copyright $\odot 2006$ by Revista Estudos Feministas

${ }^{1}$ Com a colaboração de Adriana Tanese, mestra em Ciências da Religião pela PUC-SP.

${ }^{2}$ SC HIENBING ER, 2001.
} 
Naspáginasque se seguem, vamos ouvir Ivone Gebara, religiosa da Congregação das Irmãs de Nossa Senhora Cônegas de Santo Agostinho, doutora em Filosofia e Ciências Religiosas. Ela é uma das expoentes da Teologia Feminista (TF) brasileira. Filha de pais imigrantes libaneses e sírios, com 22 anos entrou para o convento, nos anos da efervescência daquela que foi chamada a "opção pelos pobres" da Igreja Católica. Morando em Recife, participou intensamente, a o la do de Dom Hélder Câmara, da organização das Comunidades Eclesia is de Base e da elaboração da Teologia da Libertação (TL).

Sua vida junto às mulheres de Camaragibe e a a proximação do movimento feminista leva ram-na a diferencia r sua reflexão, pela incorporação do olhar de gênero. A solidariedade para com os pobres, e sobretudo para com as mulheres cujas lutas diárias pela sobrevivência ela observa diretamente no bairro onde mora, uniu-se à fineza de uma produção intelectual consistente e deu forma ao seu pensamento teológico feminista. Sua biografia inclui a docência em Institutos e Faculdades de Teologia, no Brasil e no exterior, e várias obras publicadas, em forma de artigos e de livros. Também parte de sua história são os dois a nos de silênc io forçado a que o Vatica no a condenou, porconsiderar inadequado seu pensamento sobre uma questão polêmica na Igreja Ca tólic a: a validade do recurso a o a borto. Fruto desse tempo passado fora do Brasil, na Bélgica, onde concluiu um doutora do em Sciences Religieuses, foi um de seus livros, em que aborda a questão do mal: Rompendo o silêncio: uma fenomenologia feminista do mal. ${ }^{3}$ Uma de suas últimas obras, de ca rá ter auto biográfic 0 , intitula-se As á guas do meu poç $0 .{ }^{4}$

Nesta entrevista, Ivone aborda questões candentes da abordagem teológica feminista. Discute as semelhanças e diferenças entre a teologia feminista contemporânea, européia e norte-a meric a na, e a brasileira. Fala de como se enriquecem e, ao mesmo tempo, se distanciam. A teologia feminista brasileira caracteriza-se, por um lado, por ser teologia de acadêmicas que geralmente não pertencem a instituições religiosas e, por outro, pelo fato de as teólogas estarem freqüentemente engaja da s em movimentos socia is, a rticula das com o movimento de mulheres. A maior contribuição para a teologia feminista brasileira vem certamente do movimento feminista e, avalia Ivone, quando essa teologia acompanha as questões quotidianas das mulheres, produz uma ruptura que a afasta do pensamento institucional e a separa também da Teologia da Libertação, que é a inda patriarcal e está repleta de imagens masculinas de Deus.

Sua reflexão é, assim, enriquecida pela contribuição da vivência concreta que abre o olhar para o fato de a necessidade da coerência ética não pertencer somente aos setores religiosos. Realidade plural, as teologias feministas

${ }^{3}$ GEBARA, 2000.

${ }^{4}$ G EBARA, 2005. 
expressam e perseguem o que ela chama de "intenciona lida des específic as". Surgem as teologias feminista s negra, lésbica, indígena, queer, womanist e outras.

Sua interpretação da condição das mulheres dentro da Igreja é particularmente expressiva, pois Ivone é uma das poucas religiosas que ousaram desafiar publicamente prec eitos ca tólic os considera dos obsoletos em determina das c irc unstâncias socia is. Mesmo a ssim, ela permanece ca tólica . Quisemos então saber como Ivone concilia essa contra dição existencial, presente, silenciosamente, no íntimo de muitas mulheres. Ivone fala dessa difíc il c oncilia ção entre ser ca tólica e feminista. E a presenta, critic a mente, sua comp reensão das razões que tomam a presença feminina tão numerosa na Igreja.

Como outras teólogas feministas, Ivone desenvolve uma reflexã o crític a sobre a a propriação religiosa dos corpose da sexualidade das mulheres. A visão cristã negativa da corporeida de, devida à compreensã o dua lista tra dicional que prioriza 'o espírito', a c a ba pora tribuir à s mulheres, responsá veis pela reprodução da espéc ie, um lugarnão a pena s sec undá rio, mas de periculosidade. Daí, a necessidade de controlá-las. Essa compreensão reduz a s mulheres à especificida de de sua condição biológica, em que a maternida de, físic a ou espiritual, to ma-se um destino obrigatório. A rejeição do recurso à biologia para explicaro ordenamento social - e religioso - dos sexos leva a uma crítica radical da organização das instituições religiosas, a pontadas como androcêntricas, hierárquicas e excludentes das mulheres.

Ivone Gebara dedicou alguns dos seus trabalhos teóric os à questão do corpo e da sexualidade. Aqui, ela fala sobre o lugar desses temas na Teologia Feminista brasileira e como ela avalia essa inclusão. Frisa que hoje é de particular importância pensar teologicamente a respeito da manipulação religiosa do corpo feminino, o que envolve evidentemente outros âmbitos, como a medicina, o direito e a política.

As relações entre a Teologia da Libertação e as Teologias Feministas constituem um capítulo à parte na história da elaboração teológica na América Latina e, em especial, no Brasil. Apesar da atualidade da questão ética de fundo que marca a Teologia da Libertação, esta se situa num momento específic o da história do nosso continente. É bom frisar que o c lamor da TdL porjustiça social não inc luía justiça e igua lda de de gênero, que a inda não estavam claramente em pauta naquele contexto social e político. Considera Ivone que a $\mathrm{T}$ perma neceu encerra da num id eá rio a bstra to, não enfrentando a realidade colocada pela concretude da corporeidade e do sexo. Nenhum a vanço signific ativo no campo da Teologia moral pode seraponta do na produção da $\mathrm{T}$. Para Ivone, não é possível fazer TF abstraindo-se dos corpos e da sexualidade das mulheres. É aí que começa a opressão das mulheres e que a possibilidade de sua autonomia se efetiva. Na sexualidade, frisa a teóloga, confluem desde os problemas da injusta divisão do trabalho até a dominação masculina, 
que continua pretendendo privar as mulheres da liberdade de decisão sobre seuscorpos. Exemplo disso é a a mbigüidade em tomo do debate sobre a descriminalização do aborto, expressão ma is uma vez da tentativa de mantera dominação patriarcal sobre as mulheres, inclusive porparte das igrejas.

A TF que emerge da fala de Ivone Gebara é radical e crític a. A perspectiva ana lític a que toma as relações de gênero como vetor da análise permite compreender como essas rela ções cortam transversa Imente todas as c lasses e questões socia is. Permite perceber que igualdade entre mulheres e homens está longe de ser uma realidade tanto na sociedade como na Igreja Católica. Mas permite também propor o estabelecimento de novas formas dessas relações, como condição imprescindível para que a justiça se realize. 
Maria José Rosado-Nunes: Qua is são a seu ver os temas emergentes e mais relevantes que estão no centro da reflexão da Teologia Feminista contemporânea, ou das teolog ia sfeministas, e se você está de acordo com este plural?

Ivone Gebara: Penso que no centro da reflexão das teologias feministas está uma intencionalidade de base que se expressa na a firma ção da dignida de feminina a tra vés de múltiplas formas. Essa s teologias são marca da s pelos contextos diferentes em que nascem e por algumas problemáticas diferentes, dependendo do objetivo imediato perseguido.

Costumo chamar esses objetivos específic os ou imediatos de intencionalidades específicas, visto que partem da preocupação de grupos específicos como as mulheres negras, indígenas, lésbicas, trabalhadoras do campo, emprega das domésticas, etc. É a partir daí que se pode falardas diferentes teologias feministas. Nem sempre essas teologias são escritas, mas elas se expressam na vida cotidiana e nos múltiplos encontros de mulheres. Somos nós as assessoras que muitas vezes escrevemos sobre elas.

É bom lembrar que algumas teólogas trabalham o resgate das mulheres na Bíblia, outras, as imagens de Deus, a teologia antiga e a contemporânea, porém, sempre direcionada à sua intencionalidade específica. Além disso, podemos encontrar teologias feministas que fazem um trabalho de des-construção da teologia patriarcal a partir de diferentes temáticas, seguindo de certa forma as divisões clássicas dos estudos teológicos.

No a tual momento penso que é urgente pensarmos nas diferentes formas de manipulação religiosa do corpo feminino. Essa manipulação não se faz necessariamente a partir dos representantes das hierarquias religiosas, mas também a través de políticos, a tra vés da medicina e do direito.

MJ : Essa s questões estã o presentes ta mbém na Teolog ia Feminista brasileira? Ou emergem outras? A TF brasileira também pode ser dita no plural?

IG: De certa forma essas questões também estão presentes, sob retudo nas teólogas que ensina $m$ em faculda des e instituições teológicas. A teologia norte-americana e a européia foram fonte de inspiração e de reflexão de conteúdos novos para todas nós. Entretanto, há algo de específico na Teologia Feminista do Brasil e de alguns países latino-americanos. Esse específico situa-se em uma dupla perspectiva:

a) a Teologia Feminista no Brasil, na grande maioria das vezes, se desenvolve à margem das instituições religiosas. Mesmo se as teólogas são marca das por uma pertença institucional, sua teologia não é necessaria mente dirigida a esta ou aquela igreja;

b) grande parte das teólogas feminista s brasileiras a lia seu trabalho acadêmico e produção intelectual a uma militância nos 
movimentos socia is. Essa militância ocorre, sobretudo, na forma de assessoria aos movimentos populares ou na forma de cursos regulares dados, por exemplo, ao MST, ao movimento de trabalhadoras rurais, movimento de domésticas, grupos de mulheres da periferia, grupos de consciência negra, quadros sindica is femininos, etc. Essa inserção social e polític a da teologia feminista nos movimentos de base vem permitindo uma a bordagem interd isc iplinar a partir de vivência s concretas, a ssim como um desenvolvimento exterior às instituições oficia is de reprodução das igrejas. Começamos a perceber que a busca de espiritualidade e de coerência ética não se situa apenas no interior das instituições da religião. Nesse sentido, ta mbém a Teologia Feminista no Brasil se expressa de forma plural, e é este pluralismo que faz sua riqueza e originalidade.

MJ: As teorias feministas tiveram um desenvolvimento intenso nos últimos anos. No caso do Brasil, também o movimento feminista intensific ou sua atuação, ganhando um lugar destacado entre os movimentos so ciais. Como essas teoriase o movimento de mulheres desa fiam e/ou articulam-se com a/as Teologia/s Feminista/s?

IG: Creio que a Teologia Feminista no Brasil começa a se desenvolver de forma ma is original a partir do momento em que se a rtic ula à squestões levantada spelo movimento feminista. Nosso público não se restringe a os freqüenta dores assíduos das igrejas e nem aos seminaristas e religiosos, mas abre-se para os que se debatem com as grandes questões levanta dasna soc ieda de atual e que têm um referencial religioso cristão ou outro. A meu ver, essa squestões têm a ver, em grande parte, com a violência contra a s mulheres nas suas múltiplas facetas; tem a ver com o controle da sexualida de feminina, com as questões rela tiva sà rep rodução, com a questão da la icidade do Estado e outras questões a fins. Quando as teologias feministas se articulam aos movimentos feminista s e fa zem de sua s questõ es a squestões cotid ia na s vividas pelas mulheres, se dá uma espécie de ruptura em relação às questões tradicionais da teologia e à sua forma de abordagem. Mais uma vez, essa maneira de fazer teologia não é institucional, no sentido de não ser assumida oficialmente pelas igrejas. Desenvolve-se à margem e por isso muitas vezes é difícil manter sua reprodução e crescimento, visto o caráter asistemático em que se a presenta. Nesse sentido, talvez precisaría mos criar formas de a tua ção ma is organiza das para ga rantir uma vivência e uma teoria teológica que acompanhe o avanço dos movimentos feministas.

MJ: Quais foram ou ainda são os pontos de maiores contatos e enriquecimento entre a Teologia da Libertação e a Teologia Feminista? Como a Teologia Feminista articula as reivindicações feministas com aquelas de justiça social, uma vez que as preocupações com a questão social estão na origem da TF? 
IG: Os pontos de maior contato estão na perspectiva ética encontrada nos textos do Evangelho. A Teologia da Libertação se estruturou em tomo da opção pelos pobres, dos op rimidos, como critério para a reconstrução do mundo, como base para o processo de salvação. Essa matriz ética presente nos profetas e profetizas e na tradição de Jesus é retomada igualmente pela Teologia Feminista. Entretanto, a maior parte das teologias feministas separa-se de certa forma da teologia masculina da libertação quando se trata da manutenção da dogmática patriarcal, das imagens de Deus masculinas e de um conceito de salvação estreito que inclui a penas a pessoa individual de Jesus de Nazaré.

MJ: Você poderia fazer um balanço da Teologia da Libertação? Como você a avalia hoje?

IG: A Teologia da Libertação, embora aborde problemas éticos e esse particular mantém sua a tualidade no presente, não deixa de ser a expressão de um momento histórico particular vivido na América Latina. Trata-se das décadas 1970 e 1980, período de luta contra as ditaduras militares e de afirmação de vários movimentos políticos e socia is com o apoio das igrejas cristãs. 0 cená rio mundial e as referências a o socialismo histórico da época davam a base teórica para afirmara possibilida de de estabelecer relações sociais mais justas. Davam igualmente um referencial históric o socialista a partir do qual 'se imaginava' que o povo que vivia no bloco socialista experimentava a justiça social em seu cotidiano.

Entretanto, com a mudança do contexto intemacional a partir de 1990, isto é, do final da guerra fria, do final da União Soviética, da queda do muro de Berlim e do estabelecimento da cultura e da economia globalizada, as referências socia is e também as teologias mudaram. Assim, nesse novo contexto, as teologias da libertação perdem seu referencial histórico ou, em outros termos, perdem uma certa referência histórica de sociedades justas e igualitárias. Havia, como acenei anteriormente, uma espécie de 'crença' de que nos países soviéticos havia mais justiça e que bastava nos aproximarmos desse modelo para que conseguíssemosos mesmos resulta dos. É bom termos presente que o disc urso sobre a justiça social não inc luía a justiça e a igua lda de de gênero.

Hoje, penso que as teologias da libertação no Brasil vivem na memória dos que a iniciaram e de outras pessoas que delas viveram. Entretanto, da maneira como foram formuladase vividas nos anos 1980, não penso que têm força atual e futuro promissor. A Teologia Feminista, sem dúvida, inspirou-se na Teologia da Libertação em muitos a spectos, como afirmei anteriormente, porém, dados os diferentes temas que trabalha e as alianças com o movimento feminista, ela tem se afastado da ortodoxia da $\mathrm{T}$. 
MJ: Qual é o lugardo corpo e da sexualidade na Teologia Feminista no Brasil?

IG: A partir do corpo e da sexualidade feminina é que se expressa a opressão e a dominação de gênero ou do gênero masculino. Não se pode fazer Teologia Feminista sem falar dos corpos femininos e especificamente da sexualidade feminina. Esse é o lugar a partir do qual começa a opressão e também o lugar a partir do qual se afirma a autonomia feminina. É a partir daí que se marca a posse masculina sobre as mulheres. Por isso, ultimamente tenho insistido muito no fa to de que uma abordagem feminista a partir das relações de gênero deve explicita ra questão da dominação a partir da sexualidade. Essa dominação se expressa através de uma divisão injusta do trabalho social e doméstic 0 , a tra vés de uma legislação que a caba mantendo não apenas os privilégios de classe e de etnia, mas os privilégios de gênero. Manifesta-se, igualmente, nas questões de descrimina lização e legalização do aborto, como se os homens, ou a sociedade que representam, tivessem a última palavra sobre nossa sdec isõese esc olhas. As teologia sou, ma is espec ific a mente, as igrejas seguem a mesma lógica de dominação. Afirmando-se a partir dos princípios que respeitam a vida, não percebem a contradição histórica de seus a rgumentos e a reprodução da dominação patria rcal em relação às mulheres.

MJ: Qual é o lugar que você daria a essas duas questões?

IG: Penso que esses dois lugares devem ter um tra tamento privilegiado no atual contexto teológico. E isso porque é a partir desse lugarque se dá a desigualdade econômica, política, social, cultural e religiosa em relação às mulheres. É a partir da genita lidade feminina que se constroem as diferentes simbologias e significa dos socia is em relação a o corpo feminino. Éa partir da genita lida de que se expressam os processos de soc ia liza ção desde o mundo familiar até as crenças religiosas. Portanto, é a partir dessa realidade biológica cultura lizada que é nosso ser sexuado que a cultura e as diferentes instituições sociais não apenas consideram as mulheres como seres de segunda categoria, mas organizam a política, a economia, as leis sociais, a religião de forma a sempre priorizar as iniciativas masculinas e os valores considerados masculinos.

Não se trata aqui de destacar a sexualidade ou a genitalidade do conjunto da pessoa humana. Trata-se, sim, de denunciar a forma pela qual o mundo patriarcal nos trata. Diminuem-se nossos direitos, embora se continue a falar da igualdade de direitos humanos ou da igualdade entre pessoas humanas. E a partir daí se a firma a nossa diferença para, a partir dela, a firmar-se a nossa inferio rida de na s vá ria s situa ções e instituições. Por isso, a a fima ção da diferença, embora seja um passo importante, não pode ser 
feita em detrimento da luta pela justiça e igua ldade e na linha do estabelecimento de outras formas de relação entre mulheres e homens.

MJ : Como teóloga, o que você a cha da multiplicida de de religiões e movimentos religiosos que caracteriza $\mathrm{m}$ a atualidade?

IG: A atual multiplicidade de religiões e movimentos religiosos, longe de sera expressão de uma diversida de positiva, representa, a meu ver, uma certa mercantilização do religioso a serviço do retrocesso político mundial, do retrocesso da democracia e do retrocesso do pensamento. Trata-se de uma enfermidade global na qual estamos, e o religioso parece fomecer aparentes saídas imediatas. Há uma volta aos demônios, às possessões, às ma gias e aos anjos do bem, como se a racionalidade conquistada no passa do nã o pudesse ma is explic a ras tra gédia s pessoa is e socia is que assolam nossa terra. Temos a impressão de que cresce no meio das pessoaso sentimento de abandono, de falta de sentido, cresce a desvalorização dos que não respondem aos padrões elitista s esta belecidos. Então, a projeção em forç as sup ra na tura is, em entidades metafísic as se impõe como saída. Por isso se pode dizer que o recurso às forças ocultas acompanha a lógica de dominação do Império norte a mericano e de seus sa télites.

Tenho consciência da complexidade dessa questão. A pista que abordei é uma entre as muitas que poderiam servir para analisar o fenômeno religioso em nosso tempo.

MJ : Ivone, qual ba lanço você faria da condição das mulheres na Igreja Católica hoje? Você vê possibilidades reais de mudanças favorá veis às mulheres na lgreja?

IG: Do jeito que está a instituição religiosa ca tólica romana e do jeito como se anunciam as políticas religiosas no futuro próximo, as mulheres que buscam afirmar direitos, as que lutam por uma cidadania em basesigualitárias, as que desejam uma outra ordem social e política, parecem não ter chancesna lgreja institucional. Cada vez mais ela está se tomando para elas uma referência mínima. Representa uma pertença que existiu no passado, representa influências recebidas, mas não é mais o lugar de referência de sentido e de compromisso com a transformação das rela ções injusta s. A Ig reja Ca tólic a, c omo outra sigreja s c ristã s, não são ma is para muitas mulheres os lugares de expressão e de alimento de seu compromisso cristão. Nossa pertença a essas instituiçõesé cada vez ma is complexa e problemática. Muitas vezes mantém-se por um fio tênue, visto que, quer queiramos, quer não, o cristianismo se tomou um fenômeno cultural mundial e tem um papel político que não podemos deixar de levar em conta. 
MJ: Como você explica a forte presença feminina nas igrejas, uma vez que as mulheres parecem ocupar um lugar tão desfa vorá vel?

IG: A forte presença feminina é devida à fragilização crescente das mulheres pelo sistema capitalista atual, altamente desagregador. Muitas buscam no consolo imediato que uma celebração religiosa pode dar alguma força para enfrentar os problemas do dia-a-dia. Entretanto, esse consolo imediato, na maioria das vezes, reduz as mulheres a seu papel doméstico e reforça a reprodução de um modelo de dominação masculina a domina ção dos pastores ou padres. Nessa perspectiva, é bom lembrarmos de novo que, sendo as teologias feministas não a ceitas institucionalmente, não temos um lugar a ltemativo para oferecer à s mulheres serviç os de que elas necessitam. Além disso, como não temos reconhecimento público institucional, para a maioria das mulheresnecessita das de consolo religioso é na "casa de Deus", no prédio, na igreja que se vai buscaro que se precisa. As teologias feministas nunca entra ram na elaboração da ca tequese, nas liturgias, na simbologia cristã oficial. Por isso têm um papel secundá rio na vida da maioria dasmulheres, sobretudo quando as mulheres estão necessita das de amparo e ajuda.

MJ: O que as mulheres pobres com as qua is você convive e trabalha sabem ou pensam de Teologia Feminista?

IG: C reio que as mulherespobresque vivem nos bairrosperiféric os sabem muito pouco de teologia do ponto de vista teórico. Entretanto, a lgumas são capazes de discemir o quanto as igrejas têm dado pouco lugaràs mulheres, sobretudo em relação a seus problema s específic os. Outra s mulheres vivem tomadas pela luta pela sobrevivência e poucos espaços têm para refletir sobre as causas de suas diferentes opressões. Continuam clamando por Deus e esperando a sua ajuda sem se preocupar com outras questões. Muitas vezes, em diferentes assessorias fico impressionada com a consciência política de mulheres pobres tanto do meio rural quanto do meio urbano que, através da organização a que pertencem, chegaram a um nível de análise da realidade da vida humana absolutamente impressionante. A ma ioria delas está ma is inc lina da a transforma ras rela ções socia is e a investir pouco para mudaras igrejas. Muitas a cham que não vale a pena. Acredito, entretanto, que haja uma diversida de muito grande de comportamentos nesse particular e que desconheço a maioria deles.

MJ : Enfim, sua trajetória de vida intensa e nem sempre fácil nos traz uma pergunta: como você concilia sua vocação pessoal, sua experiência religiosa e sua fé com as estruturas e os homens de lgreja que nem sempre a compreenderam e reconheceram? 
IG: Confesso que no momento não busco nem compreensão e nem reconhecimento dos homens de Igreja. Não penso que isso seja tão importante. Da mesma forma, minha pertença à instituiçã o católica romana e a uma congregação religiosa não são ma is coisas vita is em minha vida. Essa pertença tem seu relativo valor como a pertença a outros grupos. É parte de minha história e eu não seria eu sem essa história.

Cada uma de nós está em algum lugar ou em muitos lugares atuando conforme as suas convicções. Cada lugar é marcado pela a mbigüidade, por contradições e por diferentes limites. No momento não encontro razões para deixar esses lugares, visto que em outros poderia estar sofrendo das mesmas ou de outras contradições e pressões. 0 importante é que não me impeçam de pensare de tentar a firmarnossa vocação à liberdade atra vés de coisas pequenas e grandes que constituem o nosso dia-a-dia. Este é o meu presente; 0 a manhã será do a manhã. Para hoje me basta $m$ a luz do sol que brilha intensa nestas terra snordestinas e a memória de tantas pessoas queridas que povoam a minha existência.

Ivone Gebara

Camaragibe, 18 de fevereiro de 2005.

\section{Referências bibliográficas}

GEBARA, Ivone. Rompendo o silêncio: uma fenomenologia feminista do mal. Petrópolis, RJ : Vozes, 2000. . As á guas do meu poço. Sã o Paulo: Bra siliense, 2005.

SC HIENBINGER, Londa. O feminismo mudou a ciência? Ba uru, SP: EDUSC, 2001. 